\title{
Green urban economy - normative modelling approach for planning and implementation
}

\author{
Monika Bąk $^{1, *}$, and Maria Makolska-Tenold ${ }^{1}$ \\ ${ }^{1}$ University of Gdańsk, Faculty of Economics, ul. Armii Krajowej 119/121, 81-824 Sopot, Poland
}

\begin{abstract}
The objective of this paper is to present the concept of a normative model for planning and implementation of the green urban economy to supplement the city governments in the methodologies required for practical application of sustainable development. The theoretical approach is accompanied by functional verification of the model assumptions based on surveys and interviews in selected cities. Empirical studies were aimed to prepare the preliminary version of the model on the base of mind mapping approach, the review of literature and in-depth observations and analysis, and then to conduct a research testbed through the questionnaire survey (including multidimensional approach) in 18 cities in Europe and America and extended interviews with selected city representatives. It can be stated that the implementation of sustainable development demands clear and unequivocal priorities followed by the future strategies. The comprehensive model requires consideration of city governance in the context of planning and implementation process. The research validates all of the dimensions of the normative model and also provides the opportunity for experiential learning from the quoted examples from Scandinavian and Central European and countries in comparison to the USA cities.
\end{abstract}

\section{Introduction}

The climate change becomes one of the most significant global challenges nowadays. While the importance of the urban areas is systematically increasing and their role in achieving climate goals a critical issue, the discussion about the city development should place the concept of sustainability as the primary base of green city's actions. Therefore, the problem of the urban development has become commonly presented as an inseparable part of human activity and the subject of numerous scientific disciplines, including their complexity of the spatial, demographic, social, cultural, ecological and political context.

The objective of this paper is to present the concept of a normative model for planning and implementation of the green urban economy to supplement the city governments in the methodologies required for practical application of sustainable development. Additionally, the model reflects the concept of the "sustainable city" as a comprehensive system with the complexity of its infrastructural elements. The theoretical approach is accompanied by practical verification of the model assumptions based on surveys and interviews in selected

\footnotetext{
*Corresponding author: monika.bak@ug.edu.pl
} 
cities. Empirical studies were conducted in different stages of model development, firstly to prepare the preliminary version of the model on the base of mind mapping approach, the review of literature and in-depth observations and analysis, and then to conduct a research testbed through the questionnaire survey (using multidimensional approach) in 18 cities and extended interviews with selected city representatives.

\section{The theoretical framework of the conceptual model}

According to literature, normative economics is a part of economics that expresses value or normative judgments about economic fairness or what the outcome of the economy or goals of public policy ought to be [1]. Normative economics contrasts with positive economics, which aims to describe the economic world as it really is, instead of trying to prescribe ways to improve it. The normative economist tries to determine the desirabilityundesirability of various economic conditions, situations or programs by asking the question: "What ought to or should be/have been?" [2]. In this study, following the assumptions of a normative economy, a normative green urban economy model is proposed.

A normative model explains what is going on and what will happen in optimal conditions for a research object. Normative models allow to describe current roles and functions, understand the biases and develop new knowledge about further models [3]. These models are often used in the exploration of economic phenomena at various levels. For example, Vroom-Yetton-Jago model developed by Vroom, in collaboration with Yetton [4] and later with Jago [5] is a leadership model designed to help managers decide to which degree their team members should participate in the decision-making process. There are many macroeconomic normative models, for example, Heath developed three normative models of the welfare state [6] or Majila et al. proposed a model to alleviate corruption in Africa [7]. On the microeconomic scale, models can be related to competitiveness strategies, assessment of the effectiveness at the company level etc. For example model for assessing competitive strategy was developed by Ungerer and Cayzer [8] or model for determining SME IT effectiveness by Curry et al. [9].

For the model development purpose, the strong inspiration was received from the primary theoretical framework, especially strategic planning and stakeholders' theory.

Rode [10] operationalised dynamic character of integrated urban governance into four groups mechanism related to structures, planning process and policymaking, integration of instruments, and enabling conditions (Fig. 1). Therefore, the consideration of the city's arrangement, readjustment of the existing policies, financial, economic and environmental assessments, as well as the other broader set of conditions in light of the integration context of sustainable development into planning process was chosen for the analysis purposes. 
static, formal, visible
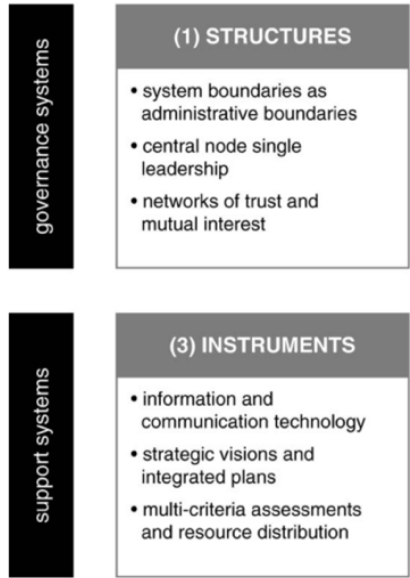

\section{(3) INSTRUMENTS}

\section{- information and}

communication technology

- strategic visions and

integrated plans

- multi-criteria assessments

and resource distribution

\section{dynamic, variable, invisible}

\section{(2) PROCESSES}

- management of interrelated

tasks and milestones

- incorporation of broader

sectoral perspectives

- collaboration of key

stakeholders

\section{(4) ENABLING}

- capacities of individuals, groups and civil society

- leadership and quality of senior officials

- knowledge, experience and collaborative culture

Fig. 1. Four principal groups of integration mechanisms [10].

Bryson [11] analysed the strategic planning process in public institutions as a sequential, step-by-step transition from the place where the organisation is situated now and where it aspires to be in the future (Fig. 2). Furthermore, he underlined out the purpose of strategic planning as the process essential for the generation of public value by the creation of efficient organisational systems to support the development of technological, social, political and cultural infrastructure and fostering the beneficial outputs for the community and urban development. The holistic use of human resources, information and financial management were also pointed out as essential for strengthening the organisational effectiveness and increasing of the public value [11]. Therefore, the analysing of the various challenges related to policy development, the definition of new mission, strategy reformulation, appropriate budget allocations as well as the assessment of offered services and further interrelations was chosen for the model creation purposes.

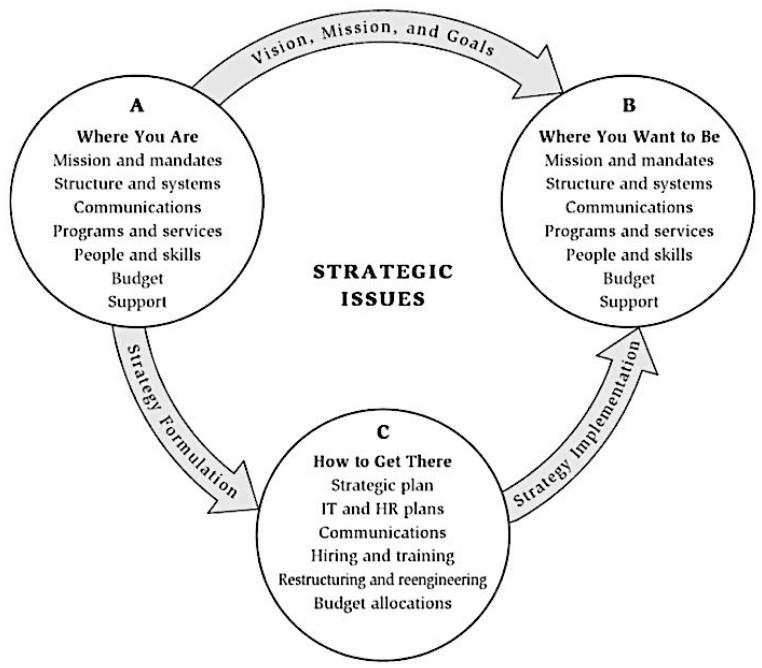

Fig. 2. The $A B C$ of strategic planning [11]. 
According to the stakeholder's theory, the corporation or the other form of business activity are affected or can affect many specific groups of stakeholders [12]. This group includes employees, investors, customers, suppliers, local communities, public agencies and institutions, media, scientific community etc. (Fig. 3.). The integration process should consist of: identification of relevant stakeholder's groups, determinations of stakeholders' importance and the efficient way to achieving their objectives, and finally to modification of the policies and priorities to incorporate those expectations $[13,14]$. It results in benefits in the form of better understanding why changes occur and the higher interest for sustainable actions for nature and urban development [15]. Therefore, the active involvement of all stakeholders in the decision-making process for sustainability in the public organisations while concluding the city's sustainable direction as well as during strategy formulation was chosen as is also relevant for the model development.

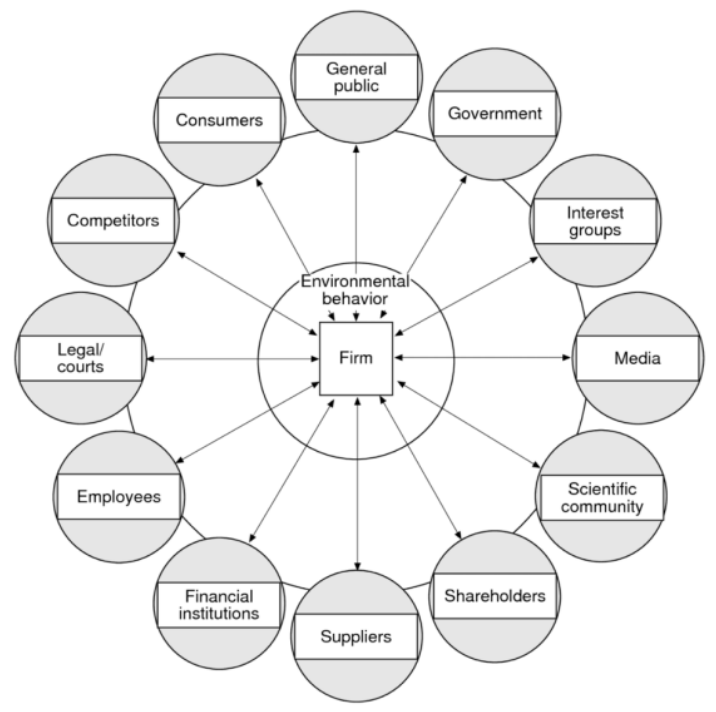

Fig. 3. Stakeholder's environmental expectations [13].

For the preparation of the normative model for the green urban economy, the methodology of the strategic-planning process was adopted from Kotler and Keller (Fig. 4.).

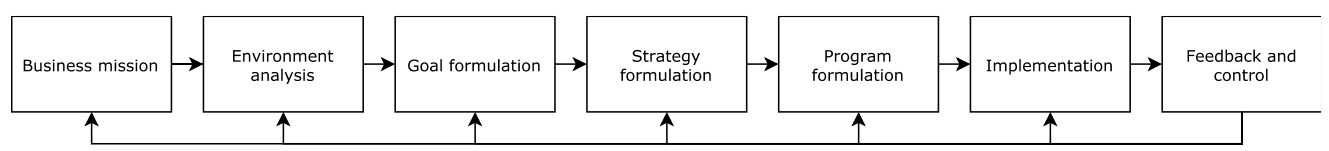

Fig. 4. The strategic planning process [16].

\section{Assumptions of the normative model}

Defined research problem of the green urban economy's implementation and its premises arising from the literature review were used for a visualisation of the critical areas for implementation of the aspects of sustainable development in cities (Fig. 5.). 


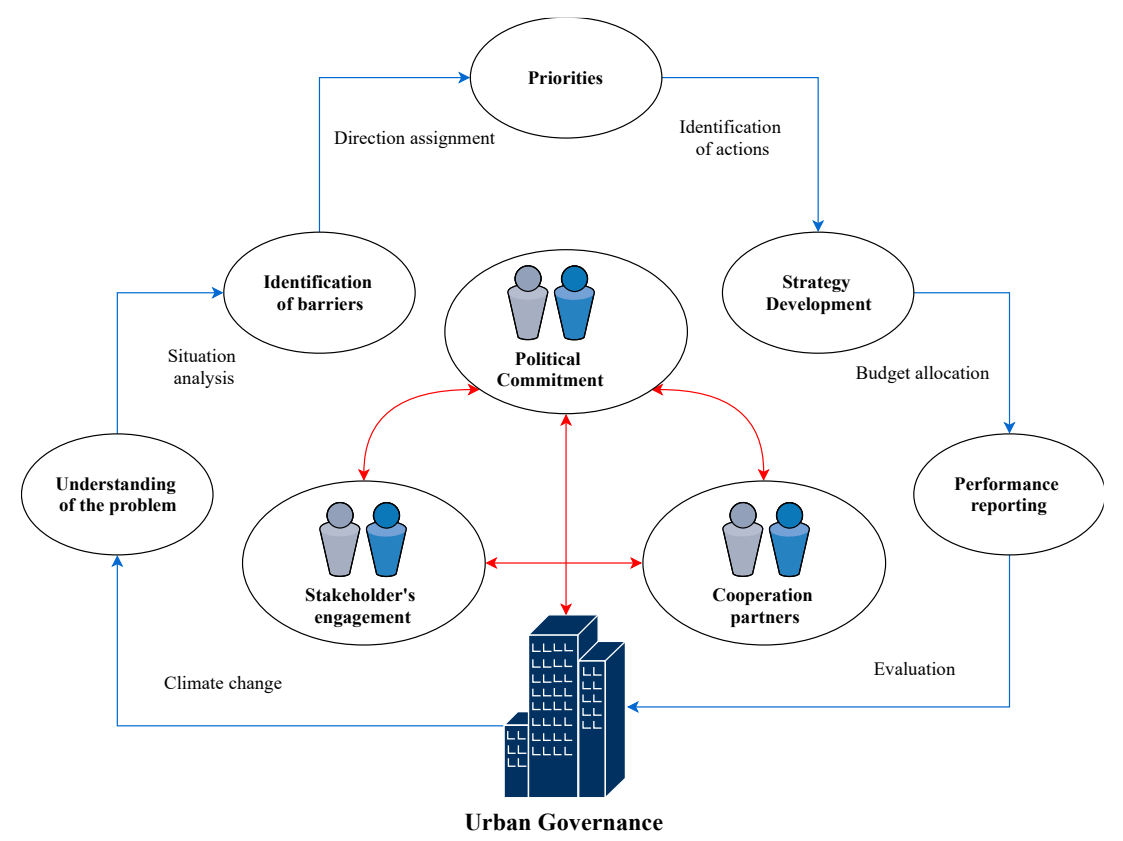

Fig. 5. The mind map for the green urban economy. Author's elaboration [17].

The constructed mind map and the inspiration received from the concepts mentioned above were used to design a following conceptual scheme for the green urban economy (Fig. 6.).

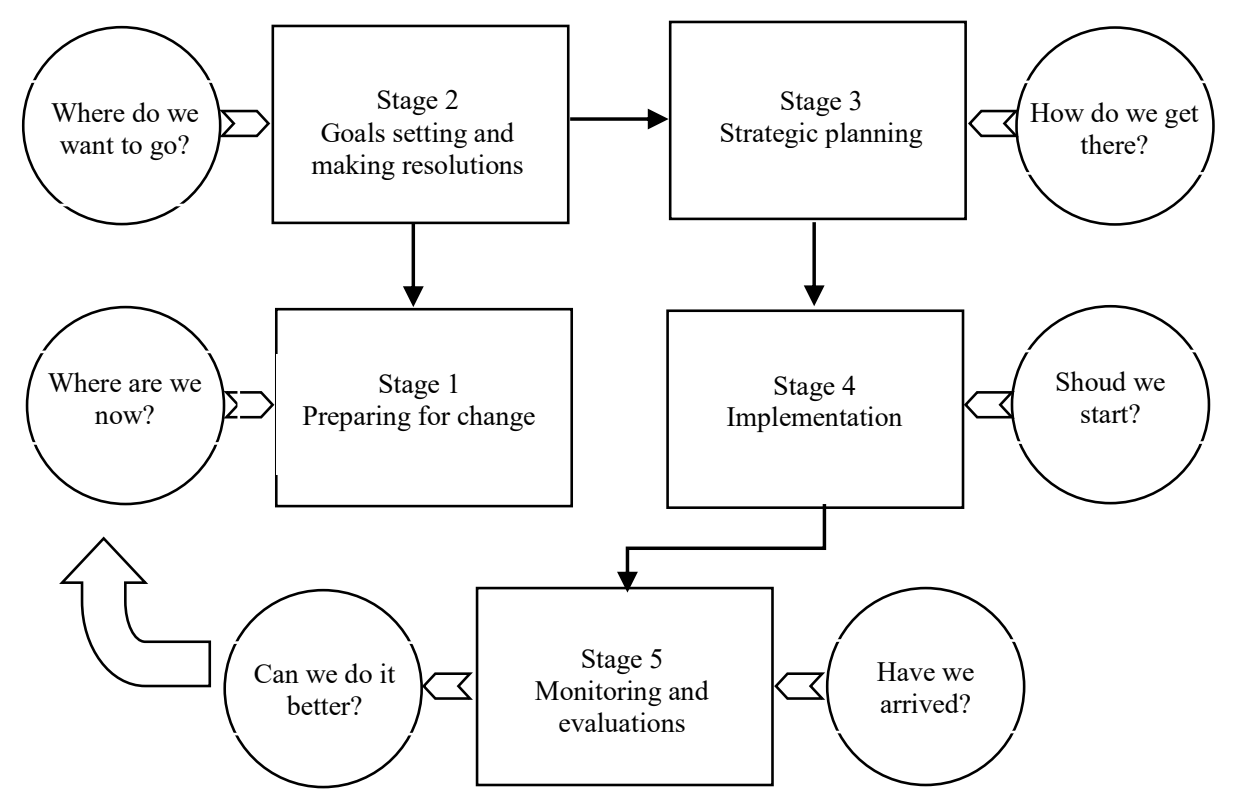

Fig. 6. Planning and implementation of the green urban economy - normative approach

This normative model (presented in schematic way in fig.6) reflects the comprehensive and dynamic nature of implementation of sustainable development in cities presented by 
the sequential strategic decision-making process for urban governance. The primary focus has been directed towards the integration of different challenges related to the identification of relevant stakeholders and their engagement in the planning process. The model also addresses the implementation's components such as the role of supportive political commitment and the importance of the establishment of multiple forms of cooperation. With the complexity of its structural elements related to policy development, it also advances the essential issues such as identification of barriers, a setting of direction and priorities, budget allocation, and performance evaluation. The model was divided into five implementation stages.

The first stage for local governments in adopting sustainable development principles (Stage 1: Prepare for change - where are we now?) begins with a clarification of present situation to identify the city's current performance, the formalisation of the political commitment to environmental issues, preparing planning team representing the expectations of stakeholders, and review of the crucial economic, social, and environmental aspects for sustainable improvements. The following requirements can be identified: to secure political commitment and financial sources, to identify and engage stakeholders, to analyse the current situation properly (including risk assessment), to create adequate administrative structure and execute the institutional adjustments.

The second stage (Stage 2: Goals setting and making resolutions - where do we want to go?) focuses on the establishment of vision, goals and objectives to define priorities for sustainable development in the city.

The third stage of the strategic planning process (Stage 3: Strategic planning - how do we get there?) requires the identification of the strategic priorities and actions, strategy development, establishment of partnerships and use of the policy instruments for achieving of previously adopted goals and objectives. Following steps forwards are identified: to identify the strategic priorities and actions, to develop strategy, to define the policy instruments, to establish partnerships and to select key performance indicators for monitoring purposes

The fourth stage (Stage 4: Implementation - should we start?) refers to the implementation of adopted strategies by cities administrations to turn plans into actions.

The last stage (Stage 5: Monitoring and Evaluation - have we arrived?) focuses on the monitoring and evaluation of the city's performance to measure the progress towards sustainable development and implementation outcomes. Finally, 'making modifications' step refers to the continuous validation of the elements of the planning process by local governments and the identification of the opportunities for the future improvements.

\section{Verification - research testbed}

The research aimed to examine how the local governments practice the concept of the green urban economy to strengthen the sustainable development in different cities. The detailed questionnaire in the form of the survey was chosen for conducting this quantitative research. The targeted group of respondents consisted of the members of local governments representing individual cities. The study was distributed online via online software platform in the period starting from the 15. Mai 2017 to the close date on 15. September 2017.

The survey was designed to specify the features and phenomena necessary for the identification of the individual process stages of the normative model for the green urban economy and obtainment of the essential information for its subsequent verification. The questionnaire was divided into five parts. The first part has been directed towards the analysis of the city's current situation and the general understanding of sustainable development, including the motivation for sustainable actions and knowledge on implementation barriers. The second part focused on policy issues. First, the respondents 
had to declare whether the sustainability was included as a goal in their city's agenda. Then, the elaboration of sustainable strategy had to be stated. The next set of questions explored on the knowledge about city's sustainable strategy and its environmental, social and economic efforts. The third part examined the process related to strategy development. The next set of questions gathers the information about the use of the policy instruments such as financing mechanisms and public procurement. First, the respondents were asked about the different financing incentives used by respondents to stimulate the sustainable implementations in their city. Then, the next set of questions explore the various procurement-related issues related to established guidelines for contractors as well as required environmental criteria for tenders. In the fourth part, the respondents were asked about their sustainable infrastructure implementations related to buildings and energy efficiency, transport, waste or water management. In the last part, the respondents were asked about the reporting and measurement of the sustainability progress. Additionally, respondents had to rate the effectiveness' of their sustainable performance.

The survey was initially sent to the largest cities in Norway, Denmark, Sweden and Poland and received 13 responses. Furthermore, to enlarge the targeted group, the location criteria were removed, and the survey became additionally forwarded to 40 individually selected cities. The study received five further responses. For the research purposes, the participant cities have been divided into three groups by the region of origin: Scandinavian, Central European, and North American (Table 1).

Table 1. The country of origin of the respondents (data as of 2017*).

\begin{tabular}{|l|l|l|r|r|}
\hline \multicolumn{1}{|c|}{ Division } & Country of origin & City & Population & Area in $\mathrm{km}^{2}$ \\
\hline Central European & Germany & Berlin & 3574830 & 891 \\
\hline Central European & Poland & Cracow & 765320 & 327 \\
\hline Central European & Poland & Gdansk & 463754 & 262 \\
\hline Central European & Poland & Gdynia & 246991 & 135 \\
\hline Central European & Poland & Lublin & 340466 & 147 \\
\hline Central European & Poland & Sopot & 36849 & 17 \\
\hline Central European & Poland & Szczecin & 404878 & 301 \\
\hline Central European & Poland & Warsaw & 1753977 & 517 \\
\hline Central European & Poland & Wroclaw & 637683 & 293 \\
\hline Scandinavian & Denmark & Aarhus & 335684 & 469 \\
\hline Scandinavian & Norway & Bergen & 279792 & 465 \\
\hline Scandinavian & Denmark & Copenhagen & 602481 & 88 \\
\hline Scandinavian & Norway & Oslo & 673468 & 454 \\
\hline Scandinavian & Norway & Sandnes & 76328 & 304 \\
\hline Scandinavian & Norway & Stavanger & 133139 & 71 \\
\hline Scandinavian & Sweden & Stockholm & 949761 & 187 \\
\hline North American & USA & Charleston, West Virginia & 51400 & 33 \\
\hline North American & USA & Denver, Colorado & 693000 & 396 \\
\hline
\end{tabular}

*Based on official national statistics of Poland, Germany, Norway, Sweden, Denmark and USA

Assuming that the study was not representative, and the results cannot be generalised to the entire communities, the other research techniques such as in-depth individual interview, observation and case study methods have been applied to obtain additional information for the testbed verification.

The validation test provides the information about the complex barriers and motivations related to the implementation process. Factors such as political support and adequate regulations have been identified as significant to facilitate the application of sustainable development. That confirms the political leadership is crucial for the sustainable performance management regardless of the specificity of cities in order to respond to the climate change. 
Research test also validates the role of engagement of the various groups of stakeholders in the planning process. The information obtained during the in-depth examination exposes the weaknesses in the majority of the Scandinavian cities in the form of low community involvement in the preparation phase. The further strategies have been formulated independently by small groups of employees in the internal departments, supported in the meantime by politicians. Despite the fact that decisions have been consulted with the City Council, it would not replace greater society integration in their undertaking and its further impact on the strategies formulated. That brings the improvement opportunities to achieve the higher community's interest in sustainable changes, additional knowledge and technological expertise, as well as external sources of financial resources for investments.

Subsequently, the test reveals that the strategic assessment of the city's current situation should be conducted in the perspective of all aspects of sustainability, to determine the future conditions for the implementation process correctly. The validation suggests the elimination of cities' knowledge gaps related to the identification of economic opportunities and profitability associated with the green urban transformation.

Moreover, the research reveals the practice of the administrative structure model form related to the shared responsibility of city's departments with the active role of the coordinator. The validation implies the dispersal of responsibility and lack of consensus between departments. The strengthening of the coordination process could contribute to the reduction of that diffusion. Subsequently, the test validates cities' vision statement. It confirms the improvement opportunities associated with the incorporation of sustainability into the formulated the vision statement in the majority of the Central European cities.

The research also verifies that the goal clarity is a reliable foundation for the future measuring of city's sustainable performance. The test indicates that the majority of cities worked actively for the counteraction of climate change by the formulation of the environmental goals. Furthermore, the research validates the identification of strategic priorities and actions. The information obtained during the in-depth examination expose that city's priorities have been determined according to the political platform of city's representatives rather than focus on the realisation of city's sustainable goals. This relation has been confirmed regardless of the cities' country of origin.

Additionally, the research reveals the coherence between the formulated strategies and their execution and outline the improvement opportunities in the application of the financing instruments for stimulation of the sustainable development. This realisation should lead to the formulation of the more pragmatic expectations and development the further realistic strategies. The verification also suggests strengthening the use of public procurement by the Central European cities to stimulate the green transition.

Then, the ability to create the collaborations and partnerships has been validated. The conducted in-depth analysis confirm the opportunities for organisational learning related to the establishment of the partnerships and collaboration between public and private stakeholders among the Central European and North American cities in order to maximise the benefits of the planning process, as well as to reduce the financial and knowledge implementation barriers.

Furthermore, the test verification exposes that cities established the ambitious GHG emission reduction targets and monitoring systems for active reporting of the results to the communities. However, the findings also reveal the opportunities for improvement concerning the evaluation of environmental performance, especially in the Central European cities. Finally, the Scandinavian cities have been found as the unquestioned leaders of the sustainable urban transformations taking into account the transparency and the rational urban politics focused on results. 


\section{Conclusions}

Summarising the overall research, it can be stated that advancing the green urban economy requires using the comprehensive layout model that include city's infrastructural condition and social and economic relations. Cities need to explore the potential of attendance of the different groups of stakeholders in the planning process and take the advantage of the opportunity of the formulation of the multi-stakeholder partnerships to strengthen the transition towards the green urban economy. The implementation of sustainable development demands clear and unequivocal priorities followed by the future strategies. The comprehensive model requires consideration of city governance in the context of planning and implementation process. Moreover, the research validates all of the dimensions of the normative model and also provides the opportunity for experiential learning from the quoted examples from Scandinavian and Central European countries in comparison to the USA cities.

Additionally, there has been identified the possibilities for the future direction of scientific research. It would be valuable to analyse the effectiveness related to the implemented strategies for sustainable development, with the attention on applied financial instruments and the use of the potential of the concept of sustainable development to build the organisational long-term competitive advantage.

\section{References}

1. A. Caplin, A. Schotter, The foundations of positive and normative economics: a handbook (Oxford University Press, Oxford, 2008)

2. The Economist Glossary of terms [Internet], Available from: https://www.economist.com/economics-a-to-z/n\#node-21529679 (2018)

3. D. J. Koehler \& N. Harvey (Eds.), Blackwell Handbook of Judgment and Decision Making (Blackwell, London, 2004)

4. V.H. Vroom, P.W. Yetton, Leadership and decision-making (University of Pittsburgh Press, 1973)

5. V.H. Vroom, A.G. Jago. The new leadership: managing participation in organizations (Englewood Cliffs, N.J., Prentice Hall, 1988)

6. J. Heath, Public Reason, 3(2), 12-43 (2011)

7. T. Majila, J.D. Taylor, K. Raga, African J Public Aff; 9, 6 (2017)

8. G.D. Ungerer, S. Cayzer, A normative model for assessing competitive strategy. South African J Ind Eng, 27(4), 34-49 (2016)

9. M. Curry, B. Marshall, P. Kawalek, Commun IIMA, 15, 1 (2017)

10. P. Rode, Governing compact cities : how to connect planning, design and transport (Edward Elgar Publishing, Cheltenham, 2018)

11. J.M. Bryson, Strategic planning for public and nonprofit organizations: a guide to strengthening and sustaining organizational achievement (Jossey-Bass, Danvers, 2011)

12. R.E. Freeman, A.C. Wicks, B. Parmar, Organ Sci, 15(3), 364 (2004)

13. M.J. Polonsky, J Bus Ind Mark, 10(3), 29-46 (1995)

14. R.E. Freeman, Bus Ethics Q, 4(04), 409-21 (1994)

15. J. Hörisch, S.E. Freeman, S. Schaltegger, Organ Environ, 27(4), 328-46 (2014)

16. P. Kotler, K.L. Keller, P. Hall, B. Columbus, I. New, Y. San, et al., Marketing 
Management. 14th_edition (Pearson Education, New Jersey, 2012)

17. M. Makolska - Tenold, Advancing a green urban economy - implementation and challenges of sustainability governance. PhD thesis (University of Gdansk, Faculty of Economics, Sopot, 2018). 